\title{
Schröder and group theory
}

\author{
Davide Bondoni
}

Published online: 6 August 2014

(c) Centro P.RI.ST.EM, Università Commerciale Luigi Bocconi 2014

\begin{abstract}
The aim of this paper is to cast light on 1874 Schröder's little pamphlet On the Formal Elements of an Absolute Algebra, devoted to the so-called "Absolute Algebra". We will show that there Schröder investigated meta-mathematically structured sets, attaining to the concepts of "group", "semi-group" and "loop". In this sense, Schröder foresaw the concept of "modern algebra", or of "group theory"; this latter in the sense of Klein.
\end{abstract}

Keywords Ernst Schröder · Absolute algebra · Group theory · Évariste Galois · History of mathematics

\section{Introduction}

In 1874 Ernst Schröder (1841-1902) (Fig. 1), then a teacher at the Realgymnasium in Baden-Baden, published as a 'supplement' a small book entitled Über die formalen Elemente der absoluten Algebra (On the Formal Elements of an Absolute Algebra) [8].

This work is usually referred to as the birth of 'universal algebra'. One of the many very interesting aspects is the clear distinction and clarification between the 'syntactic' component and the 'semantic' component in a formal theory, so much so that recently Volker Peckhaus of the University of Paderborn spoke of it in reference to the 'birth of model theory'. Two aspects strike the reader:

- At that time, Schröder had no knowledge of logic; his entire background was purely and exclusively

D. Bondoni $(\square)$

Via Bersaglio, 2, 25070 Anfo (Brescia), Italy

e-mail: davidebond@yahoo.it mathematical. He would come to occupy himself with logic only from about 1876-1877.

- The literature on Schröder, always very related to philosophy and logic, does not dwell much on the more technical and mathematical aspects of On the Formal Elements.

Our interest here is focussed on the second point, while we refer the interested reader to the specialised literature for a more logical point of view. ${ }^{1}$

\subsection{Between syntax and semantics}

We will concede ourselves a brief parenthesis on the structural conception that Schröder had of mathematics. For him, a mathematical theory was nothing more than a lattice (in the common meaning of the term) of relationships. An object drew its meaning from the position that it occupied in the lattice. For this reason, the symbols of the theory are simply marks of ink on paper, deprived of any significance. This is derived from the satisfaction of some (and not others) relations in the lattice of the theory. It is the structure of the theory in question that gives meaning to the various expressions that comprise it.

This implies a distinction between a theory that is purely syntactic-structural and without semantics, and the possible interpretations (today we would say 'models'). It is the 'syntacticalness', the extreme formalism, of the theory that allows it to be interpreted semantically in a multiplicity of ways. The syntacticalness of absolute algebra (from Latin, $a b$-soluta $=$ set free, or made separate from), or its crude formalism, consists in the fact that it has no interpretation. The elements of algebra, plainly said, are simple scribbles,

${ }^{1}$ See, for example: [1, 7]; [5, pp. 215-254]. 


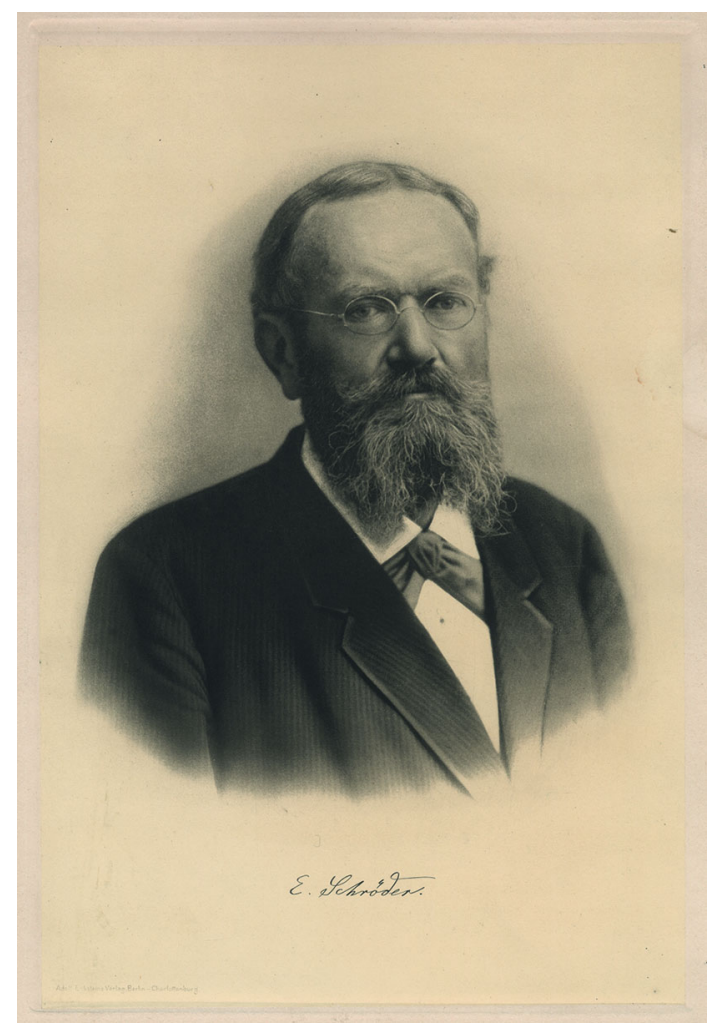

Fig. 1 Ernst Schröder in a portrait from K. Barton (ed.), Geistiges Deutschland. Deutsche Zeitgenosssen auf dem Gebiete der Literatur, Wissenschaften und Musik (Adolf Eckstein Verlag, Berlin-Charlottenburg, 1901)

liable to no interpretation at all. If Schröder did not give life to an axiomatic theory, as Frege did, he in any case announced in the space of a few lines the concept of formal theory.

\section{Algorithms}

Schröder introduced an arbitrary set $I$ of elements on which he imposed a structure, that is, he defines in $I$ a series of operations and identifies privileged elements. He called these structures by the unfortunate name of 'algorithms' and called the privileged elements modules (in our terms, neutral elements). As a matter of fact, by 'algorithm', Schröder did not mean a computational rule, but rather a set on which some operations had been defined.

Opening his book to page 14 (p. 8 in the 1874 edition), we find a list of these 'algorithms' $\forall a, b \in I$ :

\footnotetext{
2 To be truthful, Schröder used the term 'algorithm' in an ambiguous way, sometimes indicating a 'structured set', and sometimes indicating the 'operations' defined on that set.
}

$$
\begin{aligned}
& a b=b a \quad a: b=\frac{a}{b} \\
& a: b=b: a \quad \frac{b}{a}=b a \\
& \frac{a}{b}=\frac{b}{a} \quad a b=b: a \\
& a b=b: a \quad a: b=\frac{b}{a} \quad \frac{b}{a}=a b
\end{aligned}
$$

To the simple juxtaposition of elements $a, b(\forall a, b \in I)$ corresponds the product of $a$ and $b$, sometimes indicated as $a . b$. The first equality of $C_{1}$ tells us that any two elements of $I$ are commutative with respect to the product $(a b=b a)$. The second tells us that the left-division (indicated by $a: b$ ) coincides with the right-division ${ }^{3}$ (indicated by the fraction $\left.\frac{a}{b}\right)$. In $I$ structured according to $C_{1}$ there is therefore one single form of division.

The first equality of $C_{2}$ tells us that any two elements of $I$ are commutative with respect to the left-division, the second that the right-division coincides with the multiplication. Note that in $C_{2}$ it is possible for both the product and the right-division to not be commutative.

In $C_{3}$ the elements of $I$ are commutative with respect to the right-division; for the rest the product coincides with the left-division. With regard to the commutativity of these two operations, the remarks above regarding $C_{2}$ also apply here. In short, each of the first three algorithms are characterised by at least one commutative operation.

Instead, with $C_{0}$, no operation is commutative, and all three operations coincide (trivially, by the transitivity from $a b=a: b$ and $a: b=b / a$ it follows that $a b=b / a){ }^{4}$

To this group of equalities, Schröder adds modules, that is, $\forall a, b \in I$ :

$a \cdot a=b \cdot b$

$a: a=b: b$

$\frac{a}{b}=\frac{b}{a}$

These modules correspond to what we call neutral elements, respectively of the product, the left-division, and the right-division. Defining the algorithms $C_{0}, \ldots, C_{3}$ on our initial set $I$, which we also furnish with the three modules $M_{x}, M$ : and $M$, we obtain four kinds of structures. The first three are:

\footnotetext{
${ }^{3}$ I used the terminology 'left-division' and 'right-division' and the corresponding symbols introduced by Garrett Birkhoff in his Lattice Theory; see [2, p. 160ff.].

4 At page 11 of the On the Formal Elements, Schröder draws a diagram in order to explain graphically how by means of the four permutations $\mathrm{C}_{0}, \mathrm{C}_{1}, \mathrm{C}_{2}$ and $\mathrm{C}_{3}$ it is possible to move from one structured set to another; see Fig. 2. The image was recomposed in Latex by the author.
} 
Fig. 2 Diagrammatic representation of how by means of four permutations $\mathrm{C}_{0}, \mathrm{C}_{1}, \mathrm{C}_{2}$ and $\mathrm{C}_{3}$ it is possible to move from one structured set to another

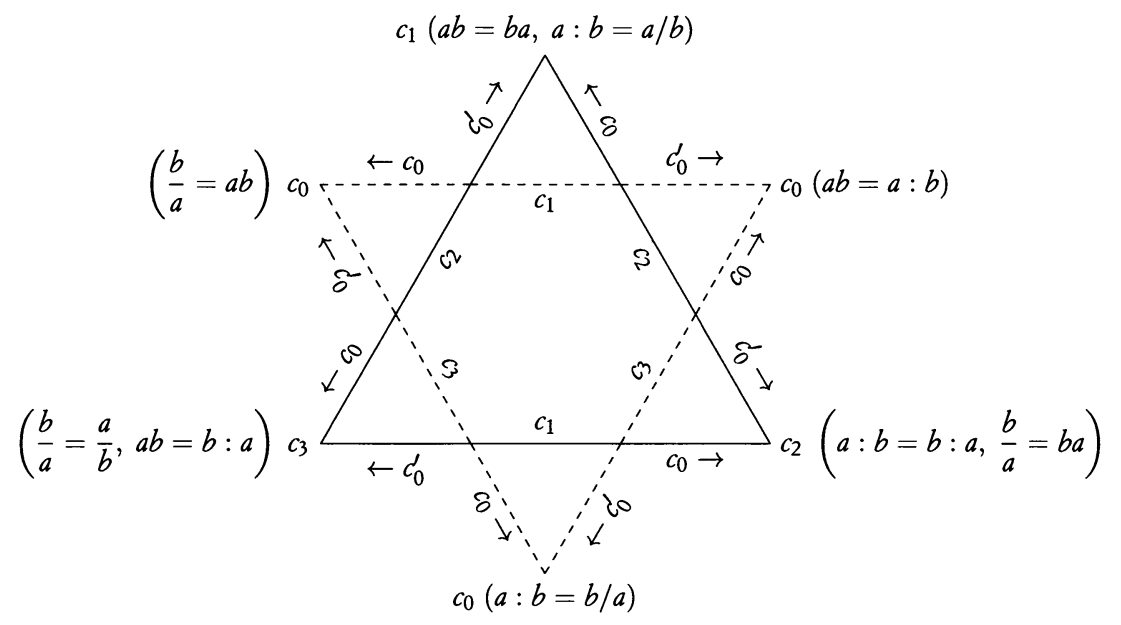

$G_{1}=\left\langle I, ., M_{x}\right\rangle$

$G_{2}=\left\langle I,:, M_{:}\right\rangle$

$G_{3}=\left\langle I, /, M_{/}\right\rangle$

As can be easily seen, these are three commutative (or Abelian) associative groups. The one exception is the fourth structure, which consists in a groupoid and whose operations are not commutative.

$G_{0}=\langle I, .,:, /\rangle$

\section{Interpretation}

As we said, Schröder doesn't speak of groups but of algorithms, even though it is clear that, when it comes to considering algorithms as structures, they coincide with our notion of group.

The notion of group was introduced for the first time by Évariste Galois in his famous first memoir ${ }^{5}$ to indicate (with a certain ambiguity) a set of permutations or $s u b$ stitutions, in function of the proof that a fifth-degree equation cannot be solved by means of radicals. For Galois a group was thus something formulated for a very defined aim. He was not at all interested in investigating the concept of group in and of itself; so much so that he confused a group of permutations with one of substitutions [6, p. 20ff]. Further, his purely combinatorial or computational conception of mathematics kept him from a structural conception of mathematical objects. In Galois's own words:

[The life of science] is rough and resembles that of minerals that grow by accretion,... analysts do not deduce, they combine, they compose: immaterial as it is, analysis is no more in our power than any other [science]; one has to spy upon it, sound it, solicit it (quoted in [3, p. 262]).

\footnotetext{
5 Mémoire sur les conditions de résolubilité des équations par radicaux (1831-1832); now in [6, pp. 106-144].
}

Did Schröder know the works of Galois? I can respond frankly no, absolutely not. He did however know the texts of Serret [9] and Jordan [4] that contributed to no small extent to the spread of the new concept of group. However, it is not even possible to infer from these texts a metatheoretical investigation of the concept of group. This would have to await for Felix Klein, who introduced that structural view of group theory that is so familiar to us and celebrated by van der Waerden in his masterpiece Moderne Algebra [10].

Schröder never returned to the topic, but the way in which he treats his algorithms is exquisitely structural. He compares the various algorithms on the basis of their power, that is, to the number of consequences might be drawn from them. In so doing, he shifts attention from the concept of algorithm (in the common meaning of the term, as something useful for a determinate aim) to that of group/ algorithm. For example, the absolute algebra mentioned in the title turns out to be a commutative Abelian group that extends the usual algebra (also because the operations are not purely formal).

It is true that Schröder dedicated only a few pages to the topic, perhaps because he was unable to realise the significance of what he was doing, but it is a shame that until now these pages have escaped the notice of historians working in group theory or in Galois theory. This is in fact the first meta-theoretical (structural) investigation of the concept of group, carried out with combinatorial means.

Translated from the Italian by Kim Williams.

\section{References}

1. Brady, G.: From Peirce to Skolem. A neglected chapter in the history of logic. Elsevier, Amsterdam (2000)

2. Birkhoff, G.: Lattice Theory, 3rd edn. 8th printing with corrections (1st ed. 1940). American Mathematical Society, Providence (1995) 
3. Goldstein, C.: Charles Hermite's Stroll through the Galois Fields. Revue d'histoire des mathématiques 17, 211-270 (2011)

4. Jordan, C.: Traité des substitutions et des équations algébriques. Gauthier-Villars Imprimeur-Libraire, Paris (1870)

5. Legris, J.: Deux approches des relations logique-mathématiques: Frege et Schröder, Justifier en mathématiques. In: Flament, D., Nabonnand, P. (eds.) Éditions de la Maison des sciences de l'homme, Paris, 2011, pp. 215-254 (French translation by Dominique Flament)

6. Neumann, P.M.: The mathematical writings of Évariste Galois. European Mathematical Society, Zurich (2011)

7. Peckhaus, V.: Schröder's logic, The rise of modern logic: from Leibniz to Frege. In: Gabbay, D.M., Woods, J. (eds.) Handbook of the History and Philosophy of Logic, vol. 3, pp. 557-610. Elsevier BV, Amsterdam (2004)

8. Schröder, E.: Über die formalen Elemente der absoluten Algebra. E. Schweizerbart'sche Buchdruckerei (E. Koch), zugleich als Beilage zu dem Programm des Pro- und Real-Gymnasium in Baden-Baden für 1873/1874, Stuttgart (1874) [Engl. Trans., On the Formal Elements of an Absolute Algebra, Davide Bondoni, edn, Milan, LED Edizioni Universitarie (2012)]

9. Serret, J.A.: Cours d'Algèbre Supérieure, deuxième édition, revue et augmentèe. Mallet-Bachelier Imprimeur-Libraire, Paris (1854)
10. van der Waerden, B.-L.: Moderne Algebra, unter Benutzung von Vorlesungen von E. Artin und E. Noether. Erster Teil: zweite verbesserte Auflage. Berlin, Verlag von Julius Springer (1937)

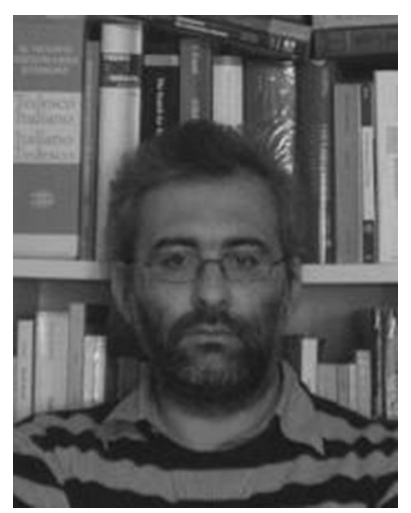

Davide Bondoni is engaged in the history of logic and mathematics with a particular interest in the figure of the mathematician Ernst Schröder (1841-1902) about whom he has written three books and several papers. $\mathrm{He}$ collaborates with the European Mathematical Society on the project of ZentralblattMATH, and is a member of the American Mathematical Society and of the Deutsche Mathematiker Vereinigung. 